\title{
Factors associated with genital chlamydial and gonococcal infection in males
}

Gavin Hart

\begin{abstract}
Background-Predictors of chlamydia and gonorrhoea can be used to increase the cost-effectiveness and acceptability of screening programmes, and allow targeting of control strategies.

Method-All men attending an STD clinic in 1988-1990 were offered screening for chlamydia and gonorrhoea, and the test results correlated with a wide range of potential predictors using multiple logistic regression.
\end{abstract}

Results-Of 9622 attenders, 7992 (82.3\%) were tested over a total of 10,110 episodes for chlamydia and 10,090 episodes for gonorrhoea, yielding $729(7 \cdot 2 \%)$ chlamydial and $123(1 \cdot 2 \%)$ gonococcal infections. Having urethral discharge and/or dysuria, being heterosexual, an STD contact, unmarried, uncircumcised, tattooed and not having had an STD previously were independently associated with chlamydial infection. Having urethral discharge and/ or dysuria, being Aboriginal, an STD contact, homosexual, uncircumcised, tattooed and having sex outside the state in the past three months, no steady partner in the past three months and multiple partners in the past month were associated with urethral gonococcal infection. Selective screening criteria for gonorrhoea provided $90 \%$ of positives, eliminated the need for $58 \%$ of tests and resulted in an increased yield ratio of $2 \cdot 2$ whereas the corresponding outcomes for screening criteria for chlamydia were $93 \%, 20 \%$ and $1 \cdot 2$ respectively.

Conclusions: The widespread influence of confounding on potential predictors for both gonorrhoea and chlamydia may provide misleading indicators of risk factors by univariate analysis. In the setting studied the benefits of selective screening for gonorrhoea in men would be substantial, whereas satisfactory criteria for selective screening for chlamydia could not be identified.

(Genitourin Med 1993:69:393-396)

STD Control Branch, Box 65, Rundle Mall PO, South Australia 5000

G Hart

Accepted for publication 29 May 1992 valent bacterial sexually transmitted disease (STD) detected in STD clinics in the USA and Europe $^{1}$ and may lead to serious complications in men and women. The epidemiology of this disease is imperfectly understood, although it appears to differ from that of gonorrhoea. ${ }^{2}$ In one study from Colorado Springs in the USA, chlamydia cases were younger and more likely to be white than gonorrhoea patients, geographic overlap of the two diseases was only about $40 \%$, with chlamydia being more diffusely distributed, and gonococcal co-infection occurred in less than $10 \%$ of chlamydia patients. $^{2}$ Cost-effective screening and other control strategies are facilitated by knowledge of predictors of infection. Whereas many studies have investigated such predictors for females, comparable studies for males are less common and more restricted in their conclusions. ${ }^{3-7}$ To provide such information all men attending a major STD clinic in a 3 year period were offered screening for chlamydia and gonorrhoea, and the test results correlated with a wide range of potential predictors.

\section{Methods}

From 1988-1990 all sexually active men attending the Adelaide STD clinic (Clinic 275) were offered testing for chlamydia (using the Pharmacia enzyme immunoassay test) and gonorrhoea (by smear and culture from urethral specimens). In symptomatic men, urethral exudate was collected on a swab from which a smear was prepared and culture plate inoculated. In asymptomatic men, a thin swab, lubricated with saline, on a metal shaft was inserted $2 \mathrm{~cm}$ into the urethra and gently rotated to obtain specimens for smear and culture. In all men tested swabs for chlamydia were collected by inserting a cotton swab on a metal shaft $2-3 \mathrm{~cm}$ into the urethra and rotating firmly. The swab was then placed in a transport tube, the metal shaft snapped and the sealed tube sent directly to the laboratory for chlamydia antigen assay. Specimens for chlamydia testing were always taken after those for gonorrhoea. Data collection and analysis using Epi Info and multiple logistic regression have been described elsewhere. ${ }^{8}$

\section{Results}

Of 9622 males (patients) attending Clinic 275 from 1988-1990, $7992(82 \cdot 3 \%)$ were tested over a total of 10,110 episodes (of diagnosis) for chlamydia and 10,090 episodes for gonorrhoea (table 1). The main reasons for declining a test were that there was no exposure since a previous test (for $215(13 \%)$ of 1,630 men not tested for chlamydia), that they only wished treatment for a specific disease (of men not tested for chlamydia, $4 \%$ had herpes and 30\% 
Table 1 Urethral chlamydia and gonorrhoea tests and results in men, Clinic 275, 1988-1990

\begin{tabular}{|c|c|c|c|c|c|}
\hline & \multicolumn{2}{|l|}{ Tests } & \multicolumn{2}{|c|}{ Positives } & \multirow[b]{2}{*}{ Yield \% } \\
\hline & No & $\%$ of all & No & $\%$ of all & \\
\hline $\begin{array}{l}\text { Chlamydia } \\
\text { First episode }\end{array}$ & 7,992 & 79.0 & 581 & $79 \cdot 5$ & $7 \cdot 2$ \\
\hline All episodes & 10,110 & 100 & 731 & 100 & $7 \cdot 2$ \\
\hline $\begin{array}{l}\text { Gonorrhoea } \\
\text { First episode } \\
\text { All episodes }\end{array}$ & $\begin{array}{r}7,992 \\
10,090\end{array}$ & $\begin{array}{l}79 \cdot 2 \\
100\end{array}$ & $\begin{array}{l}104 \\
125\end{array}$ & $\begin{array}{l}83 \cdot 2 \\
100\end{array}$ & $\begin{array}{l}1 \cdot 3 \\
1 \cdot 2\end{array}$ \\
\hline
\end{tabular}

Table 2 Risk factors for chlamydia in men (based on first clinic attendance)

\begin{tabular}{|c|c|c|c|}
\hline Factor & $\begin{array}{l}\text { Odds ratio (p-value) } \\
\text { (logistic regression) }\end{array}$ & $\begin{array}{l}\text { Crude odds ratio } \\
\text { ( } 95 \% \text { confidence limits) }\end{array}$ & $\%$ of positives \\
\hline Discharge/dysuria & $5.5\left(^{\star}\right)$ & $4.9(4 \cdot 1-5 \cdot 8)$ & $51 \cdot 3$ \\
\hline Heterosexual & $3.3(\star)$ & $4 \cdot 0(2 \cdot 4-6 \cdot 3)$ & 96.6 \\
\hline STD contact + & $2 \cdot 8\left(^{\star}\right)$ & $1 \cdot 7(1.4-2 \cdot 1)$ & $21 \cdot 5$ \\
\hline Age under 25 & $1.9\left(^{\star}\right)$ & $2 \cdot 3(1.9-2 \cdot 7)$ & $52 \cdot 3$ \\
\hline Multiple partners§ & $1.6\left({ }^{\star}\right)$ & $1 \cdot 6(1 \cdot 3-2 \cdot 0)$ & $31 \cdot 2$ \\
\hline Unmarried ${ }^{\star \star}$ & $1.7(0.0012)$ & $2 \cdot 2(1 \cdot 6-3 \cdot 0)$ & $91 \cdot 0$ \\
\hline Tattoos & $1.4(0.0041)$ & $1.5(1.2-1 \cdot 8)$ & $19 \cdot 8$ \\
\hline Uncircumcised & $1.3(0.0066)$ & $1 \cdot 3(1 \cdot 1-1 \cdot 6)$ & $43 \cdot 2$ \\
\hline No past STD & $1 \cdot 2(0.048)$ & $1.2(1.0-1.4)$ & $67 \cdot 0$ \\
\hline Unemployed & $0.9(\dagger)$ & $1.0(0 \cdot 8-1 \cdot 2)$ & $18 \cdot 4$ \\
\hline Aboriginal & $0.4(t)$ & $0.7(0 \cdot 2-2 \cdot 0)$ & 0.7 \\
\hline Urethral GC & $1 \cdot 3(t)$ & $3.6(2 \cdot 1-5.9)$ & $3 \cdot 8$ \\
\hline No steady partner|| & $1 \cdot 1(\dagger)$ & $1.5(1.2-1.8)$ & $59 \cdot 4$ \\
\hline Sex outside state $\|$ & $1 \cdot 1(t)$ & $1.1(0.9-1.4)$ & $14 \cdot 8$ \\
\hline IV drug use & $0.9(+)$ & $1.0(0.8-1.4)$ & $9 \cdot 0$ \\
\hline Warts? & $1 \cdot 0(t)$ & $0.7(0.6-0.9)$ & 11.9 \\
\hline Herpes $\uparrow$ & $1.0(t)$ & $0.6(0.4-1 \cdot 1)$ & $2 \cdot 4$ \\
\hline
\end{tabular}

${ }^{\star} \mathrm{p}<0.0001$.

$+\mathrm{p}>0 \cdot 10$

$\dagger p>0 \cdot 10$
$+S T D$ not specified.

+ STD not specified.
§in the past month.

\|in the past three months.

refers to current clinical genital infection.

$\star \star$ includes never married and formerly married.

Table 3 Risk factors for gonorrhoea in men (based on first clinic attendance)

\begin{tabular}{|c|c|c|c|}
\hline Factor & $\begin{array}{l}\text { Odds ratio (p-value) } \\
\text { (logistic regression) }\end{array}$ & $\begin{array}{l}\text { Crude odds ratio } \\
\text { ( } 95 \% \text { confidence limits) }\end{array}$ & $\%$ of positives \\
\hline $\begin{array}{l}\text { Discharge/dysuria } \\
\text { Aboriginal } \\
\text { STD contact }+ \\
\text { Homosexual } \\
\text { Sex outside state\| } \\
\text { No steady partner|| } \\
\text { Uncircumcised } \\
\text { Multiple partners§ } \\
\text { Tattoos } \\
\text { Age under } 25 \\
\text { No previous STD } \\
\text { IV drug use } \\
\text { Unemployed } \\
\text { Herpes } \\
\text { Unmarried } \\
\text { Warts }\end{array}$ & 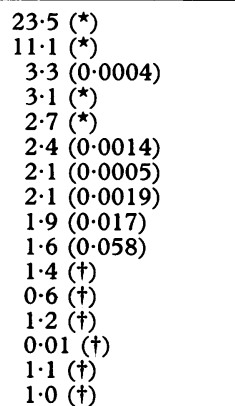 & 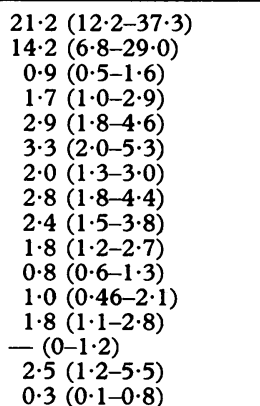 & $\begin{aligned} 83 \cdot 5 \\
10 \cdot 1 \\
12 \cdot 6 \\
18 \cdot 4 \\
31 \cdot 1 \\
76 \cdot 7 \\
53 \cdot 4 \\
44 \cdot 9 \\
29 \cdot 1 \\
47 \cdot 6 \\
59 \cdot 2 \\
8 \cdot 7 \\
29 \cdot 1 \\
\overline{92} \cdot 2 \\
5 \cdot 8\end{aligned}$ \\
\hline
\end{tabular}

${ }^{\star} \mathrm{p}<0.0001$.

$+\mathrm{p}>0 \cdot 10$

†TD not specified.

§in the past month.

in the past three months.

refers to current clinical genital infection.

$\star \star$ includes never married and formerly married.

Table 4 Confounding factors in associations for chlamydia and gonorrhoea in males

\begin{tabular}{|c|c|c|}
\hline Factor & Confounder (s) & Summary odds ratio ${ }^{9}$ \\
\hline $\begin{array}{l}\text { Chlamydia } \\
\text { STD contact } \\
\text { Urethral gonorrhoea } \\
\text { No steady partner } \\
\text { Concurrent warts }\end{array}$ & $\begin{array}{l}\text { discharge/dysuria } \\
\text { discharge/dysuria } \times \text { age under } 25 \\
\text { discharge/dysuria } \times \text { unmarried } \\
\text { discharge/dysuria }\end{array}$ & $\begin{array}{l}2 \cdot 9(2 \cdot 3-3 \cdot 6) \\
1 \cdot 3(0 \cdot 8-2 \cdot 1) \\
1 \cdot 1(0 \cdot 9-1 \cdot 3) \\
1 \cdot 1(0 \cdot 8 \times 1 \cdot 4)\end{array}$ \\
\hline $\begin{array}{l}\text { Gonorrhoea } \\
\text { Homosexual } \\
\text { STD contact } \\
\text { No previous STD } \\
\text { Unmarried } \\
\text { Concurrent warts }\end{array}$ & $\begin{array}{l}\text { discharge/dysuria } \\
\text { discharge/dyruria } \times \text { no steady partner } \\
\text { discharge/dysuria } \times \text { interstate sex } \\
\text { discharge/dysuria } \times \text { no steady partner } \\
\text { discharge/dysuria } \times \text { no steady partner }\end{array}$ & $\begin{array}{l}2.5(1.5 \times 4.2) \\
3.0(1.6 \times 5.8) \\
1.3(0.9 \times 2.0) \\
1.2(0.6 \times 2.8) \\
0.9(0.4-2.1)\end{array}$ \\
\hline
\end{tabular}

had warts), or that they perceived themselves at low risk ( $25 \%$ of non-tested compared with $15 \%$ of tested men had not had sex in the past 3 months). Of 698 men infected with chlamydia, $27(3.9 \%)$ had two episodes and two $(0.3 \%)$ had three episodes of infection. None of the risk factors studied (table 2) was independently associated (by logistic regression) with multiple episodes of chlamydial infection. One $(0.8 \%)$ of the 122 men with urethral gonococcal infection had two episodes of infection. The small number (20) of episodes involving a chlamydia test and not a gonorrhoea test resulted from patients who initially refused testing (because of the pain from the urethral swab) but eventually agreed to have one swab test. Chlamydia testing was favoured over gonorrhoea testing because of the much higher yield expected from heterosexual men.

Having urethral discharge and/or dysuria, being heterosexual, an STD contact, under age 25 years, having multiple partners in the past month, being unmarried, uncircumcised, tattooed and not having had an STD previously were independently associated with chlamydial infection (table 2). Having urethral discharge and/or dysuria, being Aboriginal, an STD contact, homosexual, uncircumcised, tattooed, and having sex outside the state of in the past three months, no steady partner in the past three months and multiple partners in the past month were independently associated with urethral gonococcal infection (table 3 ).

Significant differences in the odds ratios obtained by logistic regression and by univariate analysis suggest confounding factors for the crude associations of both chlamydial and gonococcal infection. Urethral discharge and/ or dysuria was a universal confounder in these discrepant associations (table 4).

The effects on the proportion of positive cases detected, tests required to detect these cases and overall yield by applying various selective screening criteria are shown in fig 1 (for chlamydia) and fig 2 (for gonorrhoea).

\section{Discussion}

While some factors have a similar association with both chlamydia and gonorrhoea in men (such as being an STD contact, uncircumcised, tattooed and having multiple partners in the past month) there are some striking differences. Urethral discharge or dysuria is more strongly associated with gonorrhoea than with chlamydia (odds ratio $=23.5$ compared with 5.5) and Aboriginality is strongly associated with gonorrhoea (odds ratio $=11 \cdot 1$ ) but not with chlamydia. Homosexual behavour is directly related to gonococcal infection (odds ratio $=3 \cdot 1$ ) but inversely related to chlamydial infection (odds ratio $=0 \cdot 3$ ).

The widespread influence of confounding on potential predictors for both gonorrhoea and chlamydia (tables 2-4) highlights the hazard of using univariate analysis to assess risk factors. A confounding variable is one which is associated with both the disease considered and another risk factor or indicator. 


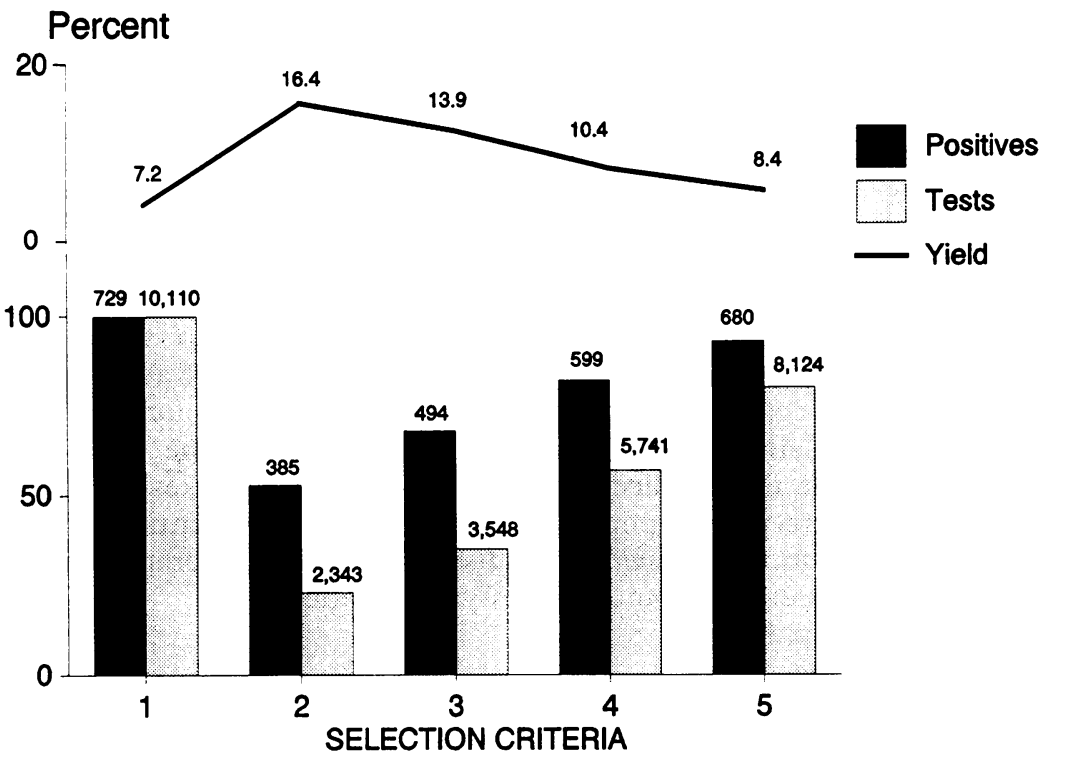

Figure 1 The proportion of positive cases detected, tests performed and overall yield (percent) for various selective screening criteria for chlamydia. Numbers of tests and positives are shown above the relevant bars. $1=$ unselected, $2=$ urethral discharge or dysuria, $3=2$ or STD contact, $4=3$ or age under $24,5=4$ or no past STD.

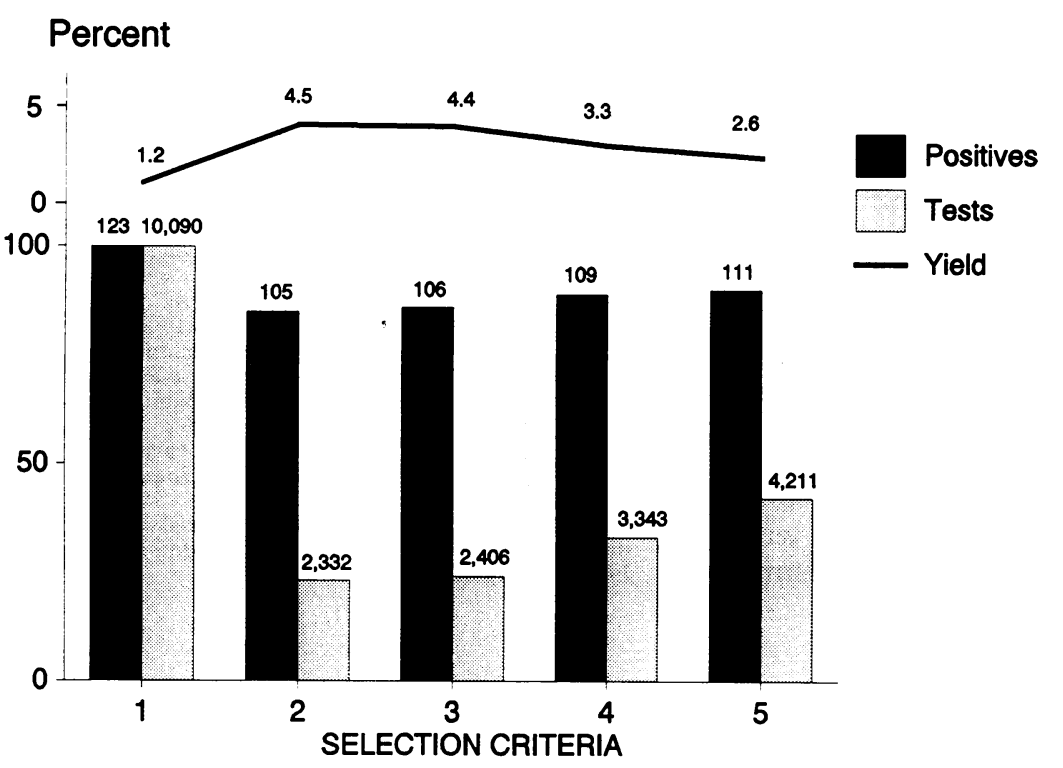

Figure 2 The proportion of positive cases detected, tests performed and overall yield (percent) for various selective screening criteria for gonorrhoea. Numbers of tests and positives are shown above the relevant bars. $1=$ unselected, $2=$ urethral discharge or dysuria, $3=2$ or Aboriginal, $4=3$ or sex outside the state, $5=4$ or homosexual.

For instance a simple tabulation of STD contact by chlamydia shows an odds ratio of 1.7 (table 2). However, tabulation of STD contact by chlamydia for men with urethral discharge is 3.4 and for men without urethral discharge is 2.7 and averaging these values in proportion to the men with urethral discharge and without urethral discharge (that is, a weighted average) gives a summary odds ratio of 2.9 (table 4 ). The reason for the discrepancy of 1.7 and 2.9 is that men with discharge have a higher yield of chlamydia $(16.5 \%$ to $4.4 \%$ in men without discharge) and that fewer STD contacts have urethral discharge (6\% compared with $26 \%$ of non-STD contacts). Consequently the lower proportion of men with discharge (the confounder) among STD contacts artificially reduces the association between STD contact and chlamydia. When two confounding variables are considered the summary odds ratio is compiled by calculating a weighted average from four tables (for example, in table 4, for urethral gonorrhoea by chlamydia the tables would be men under 25 years with discharge, men over 25 with discharge, men under 25 without discharge, men over 25 without discharge).

Although the term "risk factor" is widely used in discussion of the variables considered, "risk indicator" is probably more accurate since some variables have a causal link to the disease but others (such as urethral discharge/ dysuria) are clearly outcomes of disease. In either case the variables give an indication of the yield to be obtained by testing patients with the characteristic. For instance, simple tabulation of urethral gonorrhoea by chlamydia shows a substantially increased chlamydia yield among men with gonorrhoea (table 2 , odds ratio $=3 \cdot 6$ ). However, a weighted average of the odds ratios of the four tables resulting from subclassification of men on age and presence or absence of urethral discharge (as outlined in the preceding paragraph) produces a summary odds ratio reflecting no difference in yield on the basis of presence or absence of gonococcal infection (table 4). In other words the presence or absence of gonorrhoea does not provide additional predictive power for the yield of chlamydia after the effects of age and presence or absence of urethral discharge have been taken into account. Furthermore age and urethral discharge are more appropriate primary predictors because they are known before the decision to test is made whereas the gonorrhoea status is only known after testing has been undertaken.

The relative merits of selective screening criteria for gonorrhoea and chlamydia can be considered using a standard that at least $90 \%$ of the infected population should be included and that a substantial increase in yield should occur (preferably an increased yield ratio, that is, selected yield: unselected yield, of at least 1.5). For gonorrhoea, restricting screening to those with urethral discharge/dysuria, Aborigines, homosexuals and those having sex outside the state in the past three months results in detecting $90 \%$ of infections, eliminating $58 \%$ of tests and an increased yield ratio of $2 \cdot 2$ (fig 2). By contrast, chlamydia screening of men with urethral discharge/dysuria, who are STD contacts, under age 25 or have no past history of STD detects $93 \%$ of positives, but only eliminates $20 \%$ of tests and gives an increased yield ratio of 1.2 (fig 1). In this environment the economics of selective screening for gonorrhoea are substantial whereas satisfactory criteria for selective screening of men for chlamydia have not been identified.

While the general principles of selective screening as elicited in this setting have widespread application, the specific findings require verification and probable modification in different clinical environments. For instance in general practice the overall prevalence of STD is likely to be much less and the behavioural background may differ even among those in designated high risk groups. In other words homosexual men attending general practi- 
tioners for non-STD related problems may have a different sexual behaviour pattern (and consequently different prevalence of STD) from homosexual men attending an STD clinic. Even in STD clinics the prevalence of gonorrhoea and chlamydia may differ widely and the current findings are likely to be more closely replicated in developed than in developing countries.

A sophisticated analysis of cost-benefit (that is, comparison of costs and benefits) and costeffectiveness (that is, considering the relative merits of alternative strategies) is outside the scope of this paper, but assessment of screening strategies must extend beyond a mere comparison of yields obtained (that is, prevalence of disease in subsectors of the population). In most clinical settings the incremental costs of individual tests may be small compared with the fixed overheads (staff, premises and non-consumables) so savings might be minimal by reducing the number of tests performed. The importance of undetected cases varies greatly with likelihood of individual complications (such as the risk of pelvic inflammatory disease in women with early gonococcal infection) or risk of disease transmission (which may be high in sexually active young men with asymptomatic infection). For these reasons most STD clinics are likely to adopt strategies to detect almost $100 \%$ of infections even if a disproportionate number of tests is required. However, in some settings where testing is heavily influenced by patient request there may be widespread testing of individuals at low risk of infection and neglect of individuals at high risk. In these situations reassessment of screening practices (by comparing the profiles of those being tested with the known profiles of gonorrhoea and chlamy- dia) may be highly beneficial.

There are few cost-competitive alternatives to selective screening strategies. Contact tracing, an expensive process due to its staffintensive nature, would be preferred in very low prevalence settings when screening is not justified, but as disease prevalence increases, screening becomes increasingly favoured. The major option for improvement in screening effectiveness involves cheaper, more acceptable screening tests. While antigen tests for chlamydia are relatively inexpensive, the need to collect an intraurethral swab makes the test unpopular for patients (as mentioned in Results) and discourages general practitioners from testing asymptomatic men.

1 Thompson SE, Washington AE. Epidemiology of sexually transmitted Chlamydia trachomatis infections. Epidemiol Rev 1983;5:96-123.

2 Zimmerman HL, Potterat JJ, Duker RL, et al. Epidemiologic differences between chlamydia and gonorrhoea. $A m$ I Public Health 1990;80:1338-42.

3 Swartz SL, Kraus SJ, Herrmann KL, et al. Diagnosis and etiology of nongonococcal urethritis. $\mathfrak{f}$ Infect Dis 1978;138:445-53.

4 Karam GH, Martin DH, Flotte TR, et al. Asymptomtic Chlamydia trachomatis infections among sexually active men. $\mathcal{F}$ Infect Dis 1986;154:900-3

5 Stamm WE, Koutsky LA, Benedetti JK, et al. Chlamydi trachomatis urethral infection in men. Prevalence, risk factors and clinical manifestations. Ann Intern Med 1984;100:47-51.

6 Rietmeijer CAM, Judson FN, Van Hensbroek MB, Ehre JM, Douglas JM. Unsuspected Chlamydia trachomatis infection in heterosexual men attending a sexually transmitted diseases clinic: Evaluation of risk factors and screening methods. Sex Transm Dis 1991;18:28-35.

7 Magder LS, Harrison HR, Ehret JM, Anderson TS, Judson FN. Factors related to genital Chlamydia trachomatis and its diagnosis by culture in a sexually transmitted disease its diagnosis by culture in a sexually transm
clinic. $A m \mathcal{F}$ Epidemiol $1988 ; 128: 298-308$.

8 Hart G. Factors associated with genital chlamydial and gonococcal infection in females. Genitourin Med 1992;68:217-20.

9 Robins J, Greenland S, Breslow NE. A general estimator for the variance of the Mantel-Haenszel odds ratio. $A m$ Epidemiol 1986;124:719-23. 